\title{
Towards an intelligent blended system of learning activities model for New Zealand institutions: an investigative approach
}

\author{
Amr Adel (iD ${ }^{1 凶} \&$ Joshua Dayan ${ }^{2}$
}

COVID-19 has accelerated the uptake of blended learning approaches all over the world. The need to restrict human interaction to reduce the possibility of infection has led to a full lockdown of all educational institutions. Blended learning is a new teaching style combining traditional and modern learning models, where the digital methods of teaching students do not completely replace the ways in which the traditional teachers used to interact with and teach the students. However, there are several challenges associated with the understanding of blended learning models and their implementation in an educational institution. With the development of these blended learning models, there have also been several challenges associated with the different ways of accepting the learning models and using them in combination. This is why this paper proposes a design for a system of blended learning activities that would provide students with a total learning model, which has not replaced the traditional learning models but has successfully utilized digital technologies and blended them with traditional learning. Therefore, they can be used along with the old way of teaching a student, evaluating how the student is performing and also how the staff are performing as teachers. This paper focuses on the development of this model for students in New Zealand.

${ }^{1}$ Whitecliffe College of Technology and Innovation, Auckland, New Zealand. ${ }^{2}$ University of Auckland, Auckland, New Zealand. ${ }^{凶}$ email: amra@whitecliffe.ac.nz 


\section{Introduction}

ue to the risk of COVID-19, schools and colleges are tackling choices about how to continue tutoring and learning while keeping their staff and learners safe. Numerous institutions have chosen to drop all in-person classes, including labs and other learning meetings, and have ordered that staff move their courses online to help prevent the spread of COVID-19. The concept of blended learning is a scenario where in-person education is combined with online opportunities, and the online materials are presented with the traditional classroom atmosphere (Thompson et al., 2019). Virtual learning is not seen as surpassing the traditional teaching methods. Therefore, the physical presence of the teacher and the student is necessary. There are several areas where attempts have been made to implement blended learning activities and approaches within the educational arenas and even in some development and training settings (Boelens et al., 2018). However, most of the time, these attempts have been reported to be extremely unsuccessful, given the lack of consensus and even lack of proper awareness about the system.

The proper mixture of both the traditional and online settings of educational delivery needs to be understood first in order to blend these systems successfully. Having an online counterpart for the traditional educational approach does not represent absolute substitution but should emphasize the traditional learning approach rather than completely replace it (Vo et al., 2017). The combination of the two approaches is not sophisticated enough to acquire digital domain integration on a daily basis. The understanding of the requirements for putting blended learning into practice requires a comprehensive model, which provides a framework of steps that lead to detailed procedures. Otherwise, there indeed are several areas where the influence of the digital world has already been accepted by both the students and the teachers.

Traditional approaches that provide some online resources are not the same as blended learning approaches following a specific framework (Kristanto, 2017). There might be situations where students are already seeking help online during their educational activity, where they are aided by the online tutors available at different online platforms. This means that they have already been receiving blended learning for a long time. However, the blend is not regarded as effective, since it is not under the supervision of educational personnel and is not a policy-bound and researched approach (Havemann et al., 2019). Since the digital world now affects everyone's lives, the life of the learners and the education providers must also be involved with blended approaches according to a systematic framework to implement it in the most effective way possible.

The major component of blended systems of learning for adoption in educational institutions is establishing necessary infrastructures to include software, hardware, office space, and internet access. Blended learning environments consist of network deployments, for instance, software infrastructure, a hardware base, a high-speed network, and a wireless network, which can enhance the accessibility and flexibility of online and face-toface learning. Consequently, prior studies (Basir et al., 2010; AlBusaidi, 2012; Spring et al., 2016; Ghazal et al., 2018; Bokolo et al., 2020) have reported insufficient measures for building an integrative technological infrastructure to host and deploy blended systems of learning. This obstruction is caused by administration concerns over deployment costs and IT infrastructure maintenance (Graham 2013). Correspondingly, administration must design a reliable blended system of learning model with Information Technology and education professionals and scholars to ensure they deliver reliable IT infrastructures that meet the teaching and learning needs of student and instructors, and they need to consider scalable plans for future work in order to increase the efficiency of infrastructures as needed (Moskal et al., 2013).

Therefore, the following would be the proposed new model for blended learning approaches, mostly focusing on the students of New Zealand (Park et al., 2016). This new design would answer the research question "What model design is required for improving reliability of blended learning capabilities in in higher education?" The paper takes into account the scenarios in which the development of the virtual learning activities is taking place in society, including the emergence of digital storytelling and gamification, and provides a detailed description of the ideas behind previous attempts to create blended learning models. Based on these findings, the new design for the blended system of learning activities model is described in detail.

\section{Previously established science learning activities model}

As mentioned, there have been several attempts to create blended learning models, but no research specifically on blended learning for students in New Zealand (Van den Bogaart et al., 2017). Therefore, the previously established models and their descriptions provide the idea of what has already been done and whether these should be modified or edited in any way to make the framework suitable for the students in New Zealand. It must be kept in mind that all the design frameworks that are right now in use have their methodology set as a unanimous approach (Fathema, 2015).

There are several approaches, such as the Science Learning Activities Model, or SLAM, which is a development of a design model for cognitive learning with a blended learning framework (Bidarra and Rusman, 2017). This is a model based on real-world issues and learnings; its sole aim is to address the problems that the students are having with the traditional learning models and also the establishment of motivational impact on the students (Frampton, 2016). It is also concerned with all the assumptions made about real-world situations and the impact that these have on the mind-sets of the students. This design has three established dimensions to the model, namely context, technology, and pedagogy (Bidarra and Rusman, 2017). These framework dimensions provide the distinct model description that makes it clear that the formal and informal contexts throughout the blended learning scenarios are made as flexible as possible with interactive and immersive technologies. The issue with that framework is security leakage on exam servers and the accuracy of attendance lists, as well as the quality and reliability of e-learning videos, due to unexpected issues such as poor network connections. In addition to that, the framework shows a lack of communication between the management and learners in terms of academic and non-academic virtual support. The framework focused mainly on delivering the teaching material to the learners through the learning management systems. With these issues, alternatives are required to maintain a high-quality education by implementing a powerful blended learning model which is capable of improving both students' and teachers' experience.

An important activity that is common in blended learning approaches is Station Rotation blended learning, which is similar to Lab Rotation Blended learning (Shaffer and Small, 2004). Both encourage students to break the monotony in the classroom by moving places, and one station is an online learning station. Given this situation, the students are only allowed to experience digital learning in rotation (Crawford, 2017). This is not the type of complete digital collaboration and blended learning activity being considered for the students in New Zealand, as they are already accustomed to creative learning models where they are 
encouraged in their creative thinking through different activities (Pilgrim et al., 2018).

Another important model in the balanced blended learning activities has been in use for a long time. The entire scenario of the blended learning approach puts forward the idea of a flipped classroom where online activities are balanced with face-to-face instructional time. The idea behind this model is to have a blended learning activity but the students would not be able to either see or work with the teacher with blended learning activity of a flipped classroom (Chellapan et al., 2018). Instead, they would be in a setting of the face to face culture where the flipped setting would be characterized by the teachers having a flipped classroom model and remote behaving coursework.

The activities also involve the self-directed blended learning model and the blended project-based model, where the primary characterization is set up by the assignment, model and other related artifacts where the students are made to use their digital abilities (Ghazal et al., 2018). One of the most important aspects here is that the online resources are not enabled by the onlinebased learning model ensured by the university, but are enabled by the students themselves (Pierce, 2017). Therefore, students in New Zealand need a better approach to be developed. The idea behind all the blended learning models that have so far been researched suggests that it would be better if the older blended learning activities were discarded and newer models were established understanding the needs of the students in New Zealand. New Zealand's students are some of the most academically proficient in the world, and so it is required that they must be provided with a better blended learning model that would also emphasize their creative thinking (McLaren, 2018).

\section{A state-of-the-art review}

Information technology is one of the most fundamental services in order to make changes in every sector of the lives of human beings. Virtual learning is very effective. In recent times, many students want to learn things online and receive degrees from the global universities or institutions. However, they are not going anywhere because they reside in remote areas. In this situation, the researchers suggest taking learning courses under a reliable virtual learning system, which can ensure that accessibility is maintained properly in well-structured environments. The main benefit of a virtual learning system is that it saves time for the learners. Today the adoption of virtual learning is increasing in most of the higher learning institutions everywhere in the world (Kut et al., 2018).

Virtual learning is the concept of digitalizing learning material and placing it online, so that both students and instructors can manage the educational process effectively. The final outcome of utilizing virtual learning is to produce e-learning supported by an online learning management system. The technological world already affects people's lives; this means that the educational arena of the students has already been infiltrated by the technological world (Pandit, 2018). It is common for blended learning to be experienced without the involvement of any framework. The students might be facing issues during their educational activities, and during that time, they might seek help online. There already are several tools in online systems that help students to inquire about their issues and receive a response from the tutor online, called "online channels" (Lu et al., 2018). However, this approach is not enough for assisting students, as it is not a well-researched and effective idea, and the learning activity is not governed or supervised by any affiliated educational institute or personnel.

Further, education is a significant factor in the life of a person. The virtual learning system contributes to improving the educational system. The key objective of virtual learning is to deliver education in a flexible and simple manner by using the internet to achieve organizational objectives and support individual learning. In this way, it authorizes people, mainly students, to take courses from any place where they can access the internet, among other platforms, such as client servers and web services, as well as peerto-peer. The virtual learning platform allows operators to access data on a personal computer. Therefore, the students can establish communication with online courses through such technical platforms (Chang et al., 2016).

Distance learning is considered a new way of learning that allows students to take classes from their own place and at any time. In distance learning, physical presence in an institution or college is not necessary. Distance learning plays a significant part in today's education system. It is useful to increase the number of programmes in a year. This education system is managed through electronic communication. Distance learning is all about obtaining knowledge and assistance through mediated instructions. In other words, it is a method of education where the students and educators do not require coming together in one place. They can use electronic mail and the Internet to deliver classes. Distance education is useful when the student is separated from the teacher. This is why most colleges use distance-learning systems (Belov et al., 2016).

Moreover, the main advantages of distance learning are saving of traveling costs, no fighting for parking places, and no waste of time. The students can spend time with their families. Another advantage of distance learning is flexibility. This educational system is very suitable for the students living at a distance. It is clearly unlike the traditional method of education in which there is a fixed time for classes. The students can take classes at their own pace. The students are not required to sit in the traditional classroom to acquire knowledge of different subjects. They can stay in comfort at home. It is a comfortable way to educate themselves. Another benefit of this system is convenience. It does not matter how far the university is situated from home. The students will be able to get education at any cost (Clark, 2020).

Distance learning, including online teaching, has been investigated for a considerable length of time (Logan et al., 2002). Various research analysis, speculations, models, measures, and assessment guidelines focus on quality web-based learning and online emergency plans (Bidarra and Rusman, 2017). What we know from research is that effective online teaching is based in results from a carefully supervised learning structure, planning and utilizing a systematic model for development. The structure process and the vigilant considerations of various structure choices affect the quality of the learning. What is more, it is this watchful planning process that will be missing in most cases in the emergency online learning systems established during COVID-19.

Therefore, it is necessary that given this scenario where the technological developments influence the learning environment in the educational field, a governed framework is introduced by scholars and educational specialists. This would provide a betterblended education environment. It is not necessary for every school, classroom and student to respond similarly to a single model of blended learning system (Nortvig et al., 2018). The learning systems offer blended learning activities as a model combined with both online and face-to-face learning experiences, but they should be customized according to the type of the school, the classroom and the students. The variation of student mentalities, classrooms and education systems in different countries is huge, and so it is necessary that the students, education system and classroom variations are well-understood before a study system is implemented.

Teamwork is a main factor that is essential for effective learning. As blended learning combines both online learning and 
classroom learning, the students can control their time, as well as speed (Dziuban et al., 2018). It also enables course applicants to work together, become involved in the discussion and render valuable feedback to others. It makes an improvement in the education system. The students can receive the benefit of a digital environment. Further, the blended learning that utilizes games, applications, and measurable programs to teach concept permits learners to engage the materials at their own pace. This method promotes deep learning and reduces anxiety. It also enhances satisfaction and confidence in students. The teachers can interact with students properly. In blended learning, the students gain involvement in class and independently manage their work during the rest of the period. They can receive help from the teachers with any problem. Therefore, it is clear to say that blended learning depends partly on technology. The learning materials are available online for the students (Otto, 2018).

One of the most notable factors in the blended learning technique is that it is highly customizable, and therefore, the students in New Zealand can also be provided with a framework designed especially for them with blended learning approaches (Khodabandelou et al., 2017). However, before this can be done, it is essential that a detailed understanding of the scenarios for the New Zealand students, classrooms and institutional activities is described in detail. The quality of study in New Zealand is extremely high, according to reports and research. It has already been statistically proven that in the entire world, New Zealand is the only country where all of the universities are ranked in the top 500 educational institutes (Porter et al., 2016). The educational model is mostly three-tiered, including the primary schools and the intermediate schools, the secondary schools, the polytechnics, and the tertiary educational institutes.

The three-tier education system is the concept of an educational system where the structure of schooling lies in three distinct school types. This begins with the compulsory education of children in their first school. It is regarded as the primary school, where the age of the students lies between 8 to 10 . After graduating from the primary studies, the children are transferred to the Middle School. In the Middle Schools, the students learn the Key Stage 2 and 3 in three to four school years. The last tier of compulsory education is the upper or high school (Borba et al., 2016). The primary school system for the children in New Zealand declares that children between the ages of 6 and 16 must either attend a school or be educated at home. In New Zealand, most students are found to be starting their education at an average age of 5 years. The schools are found to be varied in size, where the total number of students in a school varies between 100 to 2000 .

The schools in New Zealand are focused on their studies, and the usual activities in the educational fields specify that these students are usually accustomed to receiving personal attention from teachers. Practical and theoretical learning in the different areas of educational institutes are found to be encouraged in New Zealand. The students in the country are even encouraged to boost their thinking by enabling independent, critical, and analytical reflections (Johns, 2017). The schools have also started to enable extreme creative thinking, and even accepted the technological changes after the introduction of computers and internet utility in the educational fields. The outdoor activities like sports and playtime activities are also encouraged similarly to the other co-curricular and cultural activities.

The teachers in schools and educational institutes support activities outside school hours like sports teams, drama clubs, music groups, and so on. The students are also provided with opportunities for educational trips as a part of the traditional educational activities. Therefore, the natural surroundings in New Zealand and flora and fauna are also being added to the education of children (Broadbent, 2017). This gives the idea that the learning of the students is not only restricted to regular bookish education. Both co-curricular activities and recreational activities are supported by the New Zealand educational institutes and schools. The opportunities are provided to the students for their development both on the educational front and for their creative thinking abilities. Most of the schools in New Zealand are state or public schools. The government offers free education to domestic students up to 19 years of age (Chen and Yao, 2016). However, the amenities in the form of school uniforms, stationery items, exam fees and course costs are provided by the family and guardians of the students.

This provides an idea about how the educational institutes in New Zealand are facilitated by the different activities and opportunities standardized by the government of New Zealand. Indeed, the activities of the organization clarify that there indeed are set standards that make the institutes of New Zealand among the most appreciated universities in the world.

\section{Gamification of learning}

Blended learning models also introduce the gamification strategy that enables the idea behind the game-playing strategies used in non-game contexts. Game design is used for the enhancement of non-gaming contexts so that the audience and their engagement with the context, participation, loyalty, and competition can be incorporated with the educational industries (Han and Ellis, 2019). It has been scientifically explained how any form of games helps in the increase of generic motivation in people through engagement (Plump and LaRosa, 2017). Therefore, including the same strategy in education may clarify how the inclusion is even more important than in any other stream of implementation. The demonstration of the general lack of motivation in the students would clarify the reasons for thinking about including these in the educational strategies (Malfliet et al., 2018). There are two driving forces behind this strategic inclusion. One is the high rate of dropouts of students from school, and the other is the evolution of the digital world, which has been influencing the way people think, with students finding themselves more able to concentrate online than with the traditional forms of education (Stroeva et al., 2019). Since the patterns of digital use for different purposes are seen in the daily lives of people, the educational fields are also keen on utilizing technological change to attract students and help them pay better attention to their studies.

Furthermore, students in different parts of the world are involved in several gamification techniques for educational purposes beyond the traditional set of learning procedures (Manwaring et al., 2017). While the universities and the educational institutes are involving gamification techniques, several types of techniques are already in use, and it is required that for the students in New Zealand, these gamification strategies are not counted (Stroeva et al., 2019). Since students in New Zealand are already encouraged to think creatively, improved gamification techniques will further encourage the creative minds of the students.

It has been found that several formats of emerging technologies are being implemented in the educational fields. Mostly, these are unsolicited formats, but nonetheless they are found to be quite effective when the students require help from them (Montgomery et al., 2019). The format of the information sharing, and teaching is also supported by technological means, usually used for the representation of an idea through a story (Dellatola et al., 2020). The technological inputs are also supported by gamification techniques, where the elements of game playing are implemented in the techniques of studying and education. Mostly, it has been found that people use gamification strategies, like the design and 
Table 1 Expert evaluation criteria.

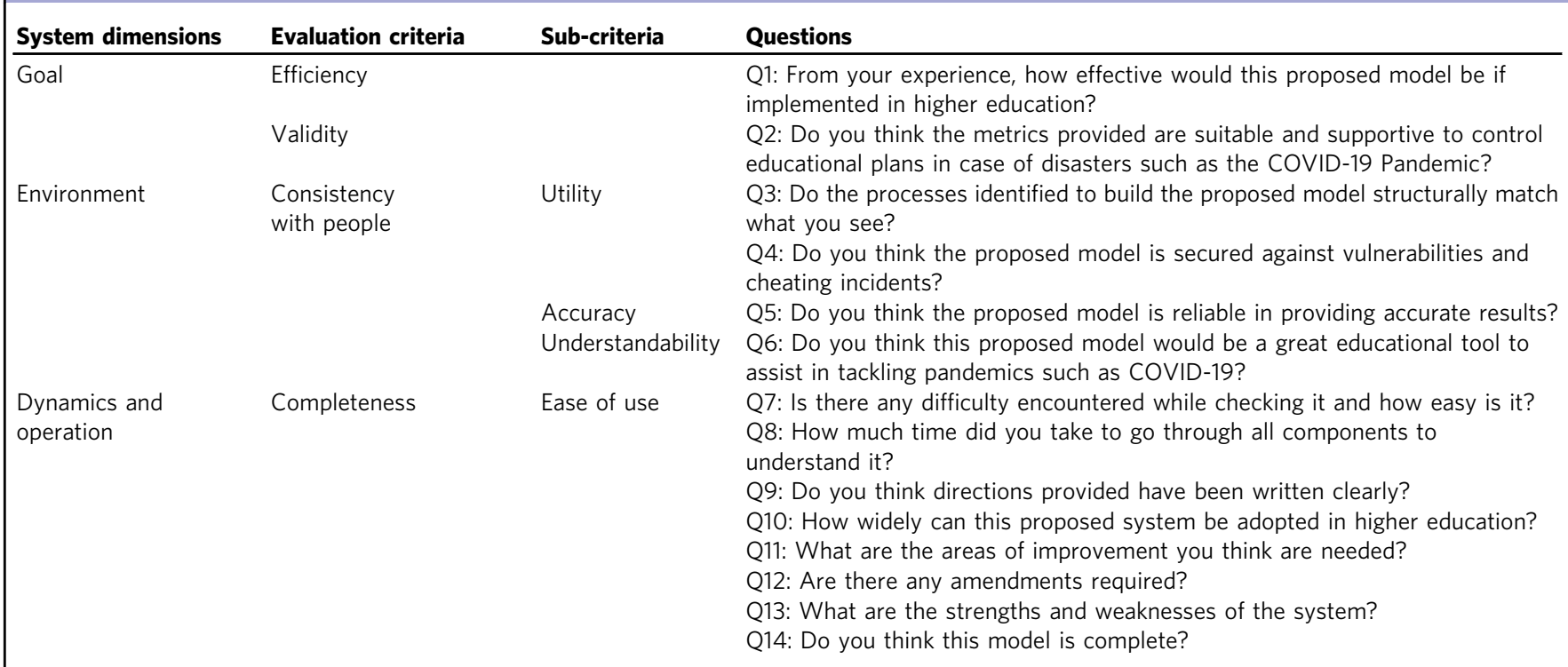

mechanics of games, for all non-game contexts, such as here in education, so that the participation of the target audience in the context is driven by the non-educational activities involving their attention more than by the usual educational activities (Zainuddin et al., 2020).

Amongst the technological fields, there are several forms of the implementation of learning techniques in digital media. The digital format enables people to share the aspects of their stories using digital media (Huang et al., 2019). The format is mostly backed by full motion pictures and sound, where the inclusion of digital technology supports the storytelling format (Medina, 2018). The other forms of non-physical media are also used in this format. The still pictures, audio-only format and the other non-physical media are also used in the form of electronic files. Actual painting and photographs can also be used for digital storytelling. This is another phase in the relatively new technological era where digital tools are used to tell a story. It covers a huge range of digital narratives and mostly takes the form of webbased stories, interactive stories, and narrative computer games (Sosa et al., 2019).

What becomes evident as we look at instances of instruction plans in emergencies is that these circumstances require creative and critical thinking (Jennex, 2020). We must have the option to think outside standard boxes to create different potential arrangements that meet the new requirements for students and communities. Occasionally, it may even assist us with finding some new answers for pandemics and unmanageable issues, for example, students challenged in attempting to continue their studies.

\section{Research methodology}

Five experts have been contacted for the critical evaluation. The five experts were selected based on their technical and research experience recognized in that area. The "Technology Education New Zealand" network was the means of getting in touch with the five experts. The process was initiated by email to confirm their availability to participate. A file including the proposed model design and its documentation, along with the questionnaire, were sent to them to be built and tested, and then validated by expert feedback. The five experts were contacted and approved to assess the model, according to design science research methodology.
The experts were given 14 days to test and validate the proposed model. All data collected from the experts was recorded and stored in a secured server for the period of one year before destruction. Table 1 shows the expert evaluation criteria, based on a systematic approach derived from Prat et al. (2014).

The evaluation process was designed to involve several specializations of computers and education throughout the assessment, so accurate results could be obtained. Each one of the experts has specialist skills in different fields, for example, technology integration, computer and educations, IT security in education, and blended learning. They have been working on integrating information technologies into education for around ten years.

Expert 1 has 11 years of industry experience as a consultant for the New Zealand government. He also has an extensive knowledge in research as professor at one of the top-ranked universities in New Zealand. He is also a reviewer for a number of reputable journals that specialize in implementing technologies in education. The oral advice that was received as a part of his feedback was very convenient for commercializing the model.

Expert 2 has 13 years of practice in IT security in education and has extended knowledge of digital forensic investigations processes to identify potential holes in the educational systems, particularly iQualify and Blackboard. He is a cybersecurity consultant for one of the big four companies in New Zealand.

Expert 3 has more than eight years of deep knowledge in the blended learning teaching style and working on managing online teaching platforms, and more than 15 years of teaching at a category one college in New Zealand. He is an assistant professor and also a reviewer for many prestigious international journals and conferences.

Expert 4 has worked in computers and education for more than ten years. He has worked as a Penetration Tester, working on a number of security reviews, including web application reviews, mobile application testing and hardware reviews of rooted devices that are connected educational platforms. Recently, he presented a number of related vulnerabilities found in current educational models.

Expert 5 is an assistant professor with an extensive knowledge in teaching papers in education for more than ten years. In addition, she is the head of postgraduate studies with a professional experience in leading and providing proper educational 


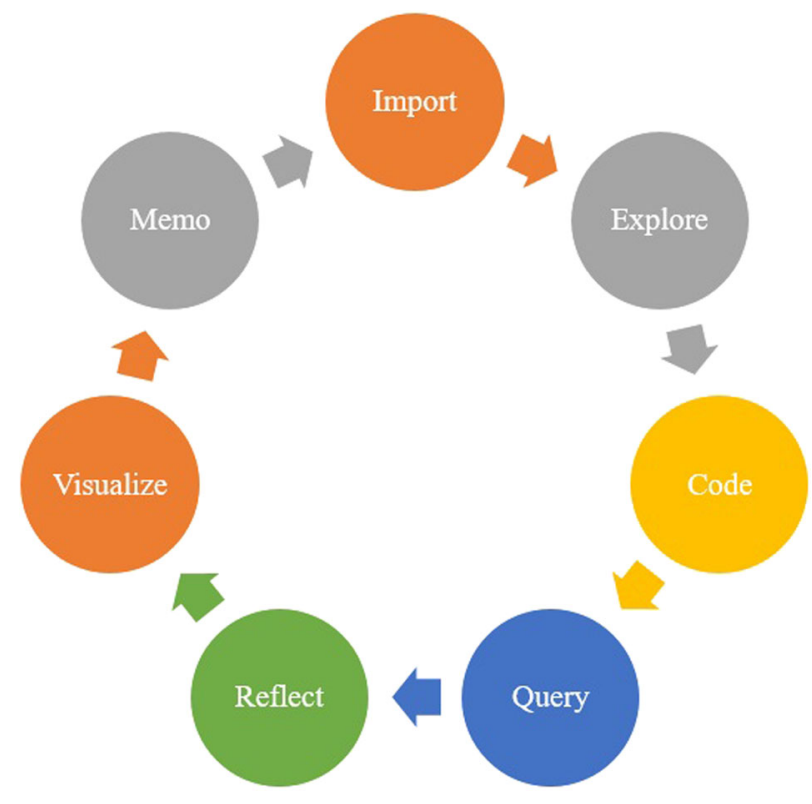

Fig. 1 NVIVO data analysis process.

platforms to students. Her experience was requested to provide an evaluation from different angles of education to improve it further. She is also one of the active researchers in New Zealand and hold many international awards.

The major objective is not only to obtain their feedback on the suitability and reliability of the given model, but also on the functionality, usability, efficiency, effectiveness of the proposed model. The data has been collected by this approach for the data processing phase. Microsoft Word is the software used for keeping the feedback on the experts' evaluation of the model proposed to evaluate its suitability and reliability. Afterwards, critical analysis was conducted using NVIVO software, which was designed for qualitative data analysis. The simulated tests were set up with VMWare Workstation to provide a safe and controlled environment for testing. Figure 1 shows the data analysis process in NVIVO.

As shown in Fig. 1, the first step to start the data analysis is to import all required documentation in order to explore experts' responses. Collecting references and links to connect keywords and major responses is a beneficial step towards achieving more exact results with a high level of accuracy. Collecting references greatly helps in conducting text search queries about particular keywords. The results of text search queries can be gathered to review all material in one place. All results can be visualized to display a word tree to see how people talk about the targeted words. At the end, the researcher can record all results in a memo for writing up the project.

Proposed model: blended system of learning activities model New Zealand education perspective in meeting maori learners' values. Explanations of a Maori style of learning involve a predilection for running in groups, face-to-face contact, and conversation, and learning that are connected to real-world scenarios (Zepke and Leach, 2002). Nevertheless, the suitability of attempting to explain a Maori viewpoint of learning in Western academic settings must constantly be doubted. Numerous authors have portrayed a Maori method of learning as managing to be complete, including all four components of the person-wairua (spiritual), hinengaro (intellectual), tinana (physical), and whatumanawa (emotional) (Barlow, 1991). Therefore, knowledge is acquired from the association that individuals have with broader methods, involving their families, the land, and the sky (Durie and Hermansson, 1990). Both historic and modern explanations of techniques for instruction and learning involve waiata (song/ poetry), whakatauaki (proverbs), korero tawhito (history), and whakapapa (genealogy). Each of these educational approaches can be utilized for teaching particular subjects, as well as for delivering courses about life (Hemara, 2000).

Returning to Western perspectives, as understanding of how adults learn increased, theories such as andragogy, constructivism, and transformational learning became popular. Andragogy is a theory of art and science which helps adult learners to learn effectively and acquire credible information through engagement and participation. According to Merriam et al. (2007) and Forrest and Peterson (2006), Knowles' perspective on andragogy is based on six main assumptions: assuming that learners are able to conduct their study independently, learners are drawing their study based on their prior experience, learners will study what they need to know, learners are studying for immediate implementation instead of looking for future trends, learners are internally motivated rather than externally, and lastly, learners need to know the value of learning and why they need to learn. Therefore, it is vital to encourage learners to think about these assumptions so they can maximize the benefits of learning and boost their knowledge to meet the challenge. Such discussions with the learners would greatly assist in gathering more feedback about the process of learning and how to further develop it to help learners with their study.

"The andragogical approach provides a guidance to design learner-centered instruction to enhance competencies" (Chan, 2010). It is important to establish a psychologically and physically conductive learning environment. In virtual classrooms, the psychologically and physically conductive learning atmosphere will help in building a collaborative environment and creating a mutual respect and mutual trust between the tutor and the learners. In addition, one of the effective methodologies that is implemented in our proposed model is virtually engaging learners in mutually planning their studies based on their learning interests and activities creating virtual communication channels. This is always leading me to learners' engagement with diagnosing their needs by defining the level of proficiency in the area of interest. This engagement would help learners to be more focused on their study, as they are aware of what they want to achieve when finishing their qualification. It is also vital to give a student space to do their own research to identify their own resources for study based on sound criteria to make sure resources of information are credible and worthy. Part of andragogy theory is ensuring that learners are being involved in virtual evaluations of the assessments to check all points one by one and make sure they are aware of the evaluation process and how it is reflected in the learning outcomes.

It is proved that a learner-centered learning approach, working together in national networks in organization with our communities, produces better results for Maori and Pasifika learners. The vision of the learner-centered learning approach is that every learner is connected, confident, and able to contribute to a thriving and prosperous economy. In order to maintain a learner-centered approach properly, we need as educators to consider the following:

- Skills, competencies, and knowledge

- Learning environments and teaching techniques

- Professional relationships

- Systems and structures

Skills, competencies, and knowledge are the key factors of learners' success. They are vital for integrating Maori and Pasifika values into the curriculums in order to create graduates who are 
fully equipped with skills, competencies, and knowledge required in industry. Learning Environments and Teaching Techniques are to be carefully considered so learners can be always motivated and thrilled to learn by preparing the suitable atmosphere for their study: "whanaungatanga, the importance of connectedness with whānau and the wider community, and of broader community involvement in learning" (Education Central, 2018). Professional relationships play an important role in connecting communities in New Zealand, especially Maori and Pasifika communities. It is important to provide equal opportunities for all learners and to give them the chance to contribute to communities and benefit from the technologies presented.

Models of delivery are needed that sustain Māori and Pasifika whanau (community) and aiga (family) for who they are, can make a trusted and safe environment, respect personal space, and share with them the necessary skills, competencies and knowledge to involve themselves excellently in their learning. For Māori and Pasifika, educational achievement is a strongly personal thought that relates to more than the young individual-it runs to and from whānau, hapū and iwi (tribe), family, community, and church.

Health and wellbeing are the key factors for any learner's success. The link between virtual education and health is recognized by the Ministry of Health in New Zealand. Therefore, they have established Māori health models. "One model for understanding Māori health is the concept of 'te whare tapa whä'-the four cornerstones (or sides) of Māori health" (Ministry of Health, 2017). They are: Taha hinengaro (mental health), which focuses on improving the ability to communicate effectively and to feel their bodies and their minds are inseparable, Taha whānau (family health), which focuses on caring and sharing, where people are part of inclusive community systems, Taha wairua (spiritual health), which focuses on the faith and all energies that are unseen and unspoken, and Taha tinana (physical health), which focuses on physical health, growth, and development. The icon used to demonstrate these well-being components is Wharenui (meeting house).

The implementation of that model in our programme design supports us in encouraging our Maori and Pasifika students by offering high-quality education that is approachable to the variable demands of their knowledge. Taking the major components of wellbeing into consideration means they can be utilized for all students, including Maori and Pasifika learners, to make sure the virtual environment of study is healthy.

Development process of the proposed model. Within the domain of blended learning, there are models to report numerous conditions surrounding both university and school contexts, mostly incoming from a traditional perspective to integrate elearning with new technologies. A comprehensive study of the relevant literature is presented by Bidarra and Rusman (2017), including their own model, called the Science Learning Activities Model, sustained by the view that 'students need to be involved in an enculturation process to alter their current epistemological attitudes, beliefs, and systems of learning. Consequently, at the early stages of students' commitment in their study through blended learning systems from their devices, teachers need to model the unified learning process by gradually and systematically incorporating e-learning activities into the formal curriculum. The major focus was to deliver the proper platform that ensures papers of science can be fully engaged theoretically and practically. We argue that, to profit from the opportunities that the Science Learning Activities Model (SLAM) spaces of today offer, we need an innovative perspective for the instructional design of science education supported by an operational model of activities. The major challenge of SLAM model is that its design created to organize the process of delivering the teaching material to students effectively with an obvious gap between the education system from learners end and education systems from management side in terms of communication. Also, another challenge for international students in New Zealand is taking the attendance manually which leads to human error in some cases. Attendance recording needs to be an automated process and included in an integrative model for blended learning style. The design of the proposed model focuses more on improving the reliability of blended learning capabilities in higher education in order to deliver a complete infrastructure full of services to teachers, students, and management to meet international, domestic, Maori and Pasifika learners in New Zealand. Communication and support from management has been taken into consideration to fill out the lack of communication gap between all management and control components and learners.

In this study, towards an Intelligent Blended System of Learning Activities Model design, which we consider a work-inprogress to establish a more fashionable and maintainable model for blended learning, a meta-analysis of other traditional models was conducted. The state-of-art review, gamification learning and learning styles were selected for this purpose, including other phases, for instance, social, governance and organizational matters. From the start, there was an interest in seeking the conjunction of the established models with an emerging one.

As has been found before, the blended learning techniques are unique abilities introduced in the educational field that correlate and amalgamate the different phases of technology and education so that the students can benefit from the different aspects of the learning model. The amalgamation of the technological fields and the traditional way of learning helps the students find different ways of effective learning. It has been found in several locations that the students are not motivated enough to study, and the blended learning models have proven to be extremely helpful in cases of the introduction of different gamification models that make them intrigued by their studies (Plump and LaRosa, 2017). The different blended learning techniques that have already been introduced in educational institutes and others for a proper learning environment have already been discussed above. The result of all these has proven to involve the children in learning activities more and more. Several distinct models include the face-to-face drivers, flexing, rotation, online lab, and online driver and self-blend. It has been found that no model really develops the technique of self-blend in terms of providing technical maintenance (Basir et al., 2010; Al-Busaidi, 2012; Spring et al., 2016; Ghazal et al., 2018; Bokolo et al., 2020). Self-blend is a type of learning activity that is developed by the students themselves when they are not finding any specific guidance to their studies while they are struggling with them.

The detailed proposition of the model. It is hard to understand the psychological prospects of a student and the hardships that they are facing with their studies. The blended learning models help the problems that the students are facing with their studies, and this is why the blended learning approach was formulated following the self-blending that students usually invent. The proposed model (Fig. 2) has been created to contain major concerns from students and teachers' perspective. Social media are the central point of teaching where all factors are linked together. Conducting an introductory session would be the first step to achieve in order to provide a basic knowledge of the target course, which is included in the proposed model to guide the students throughout the study times. Providing full-access to e-learning material is intended to support students with necessary 


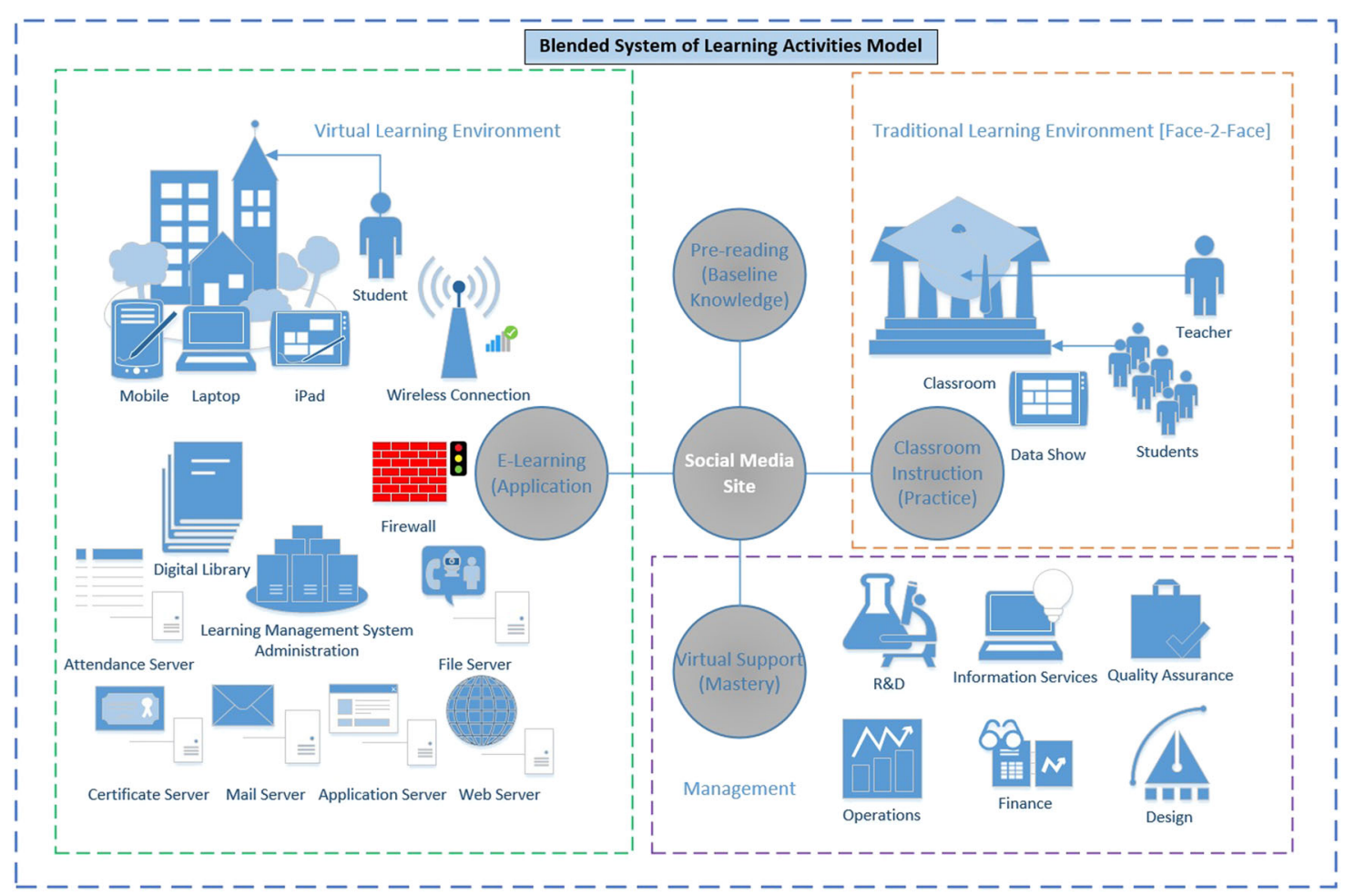

Fig. 2 Blended system of learning activities model.

information on the topic and to provide enough support for the assessment process. This would solve a problem with internet connection stability. In this case, the student would be able to access all e-learning material along with recorded sessions when they had access to the internet. Once e-learning material and assessments had been uploaded and explained to the students, the teacher could conduct virtual classes and labs with students, and customized sessions would be an option to provide one-to-one meetings. This model provides an enhanced feature of tracking students' activities in the form of system logs. This would improve the process of detecting potential cheating cases in terms of online quizzes and other online assessments. In addition to that, the proposed model is capable of supporting staff and students with an intelligent application that creates online forms with model answers hidden but is able to match students' answers electronically to reduce human error and interaction. The attendance system would be maintained electronically in stage 3 to keep tracking the attendance records of students.

As shown in Fig. 2, the proposed model ensures that the integration between the management, virtual support, and traditional learning environment are maintained properly. In virtual learning environment, learner is provided with some of the technological tools that can help in learning effectively, such as mobiles, laptops, tablets, and other electronic devices. These devices are interconnected with the institution's network so learners can access all relevant material. In this environment, all learners accounts are linked with learning management system administration that ensures the security and privacy of all resources and provide secured channels for communications. Also, attendance server is established to automate the process of recording the students' names into sessions. All other types of servers are established with a strong protection method to maintain the privacy of students' information. These servers are to host the learning management systems, issue certificate of completion automatically once courses completed, create email addresses for students for remote communications. One of most interesting part of that environment is "Web Server" and. Web server hosts all applications and tasks the students need to do in terms of school activities for science, engineering, and computing majors. The benefit of the web server is to provide virtual platforms that simulate real labs. Traditional Learning Environment is established to provide the students with necessary support on-campus and face-to-face. This environment would allow students to have face-to-face discussion or to seek one-toone support sessions. Management environment is to provide students with virtual support in terms of research \& development, some info about particular services, guidance, financial support and scholarships, course design and plans, and other types of support that student can benefit from a complete virtual platform in parallel with traditional ways of acquiring information.

The new blended system of learning activities model (Fig. 2) provides the strategy of mixing online and brick-and-mortar classroom learning so that the students have their control over the time, place, and pace of learning. It is easier to understand that a student finds it more appealing to be closer to nature and exposed to the practical world where there would be a lesser influence on the classroom environment. It is already established as a known fact that the students in New Zealand are more exposed to creative learning and they are not bound in the four walls of the classrooms. Therefore, the model that can be proposed for them would be better as a positive atmosphere that brings the student out of their class so that the students can decide on their own on what to study and how to study with closer proximity to deciding their learning materials whenever they need. For this particular purpose, a blended learning model for the students of New Zealand can be proposed, where complete digitization of the educational institutions should be introduced. The complete digitization strategy for introducing a blended learning technique would be a perfect example where the traditional learning models would not be replaced in any way, but would be substituted as per the choice of the students so that they could decide on whether they would like to have their sources and teaching styles digitized. 
The blended learning model that is to be proposed in this research paper, after extensive research by authors and experts about the students of New Zealand and the already-imposed ideas, is a complete digitization model for the universities and educational institutes in New Zealand, so that a proper substitute for the traditional methods is found, as with the different ways of introducing digital storytelling for class activities. Digitization and the digital storytelling model would be based on the ability of a student to understand their subject and use their creative abilities at the same time to evaluate and make it understandable to the rest of the interactive group. In this specific style, it would be required that the entire class was divided into several interactive groups working together. This group should be equipped with proper devices that would help them in gathering their online resources. Through the traditional form of teaching, the educators and scholars in the institute would provide the students with the required activities that would be helpful for them to gather the traditional form of learning. However, they would be evaluated on their ability to pass on the same knowledge and information to the next set of students by making them understand the entire teaching with solid pieces of evidence of digital storytelling gathered from the resources.

Since the students in New Zealand are already exposed to creative thinking, they would be encouraged more throughout the digital storytelling technique so that the enhancement of the creative mind is boosted for them and they are exposed to all the technical abilities that the recent generation must have to become leaders in society. This blended learning model can be explained with an example.

For example, consider an educational institute for management studies. The class has the help of an educator who is highly skilled at making the students understand the details about the management studies, but at the same time, the form of teaching that the teacher provides is traditional. Let the students have a class where information about a specific subject, the modernday behavioral patterns of managerial personnel, their appropriate and ideal behavior with the description of detailed reallife examples, is provided to the students with the help of traditional methods. Now, instead of a library that is available with all the journals and research papers or other books about managerial behavior, let the students be provided with the digital library where they can avail themselves of all the resources that they require for continuing research about the study for a given assignment.

The digital library would not require any other authentication than the identity of the student. This particular authentication service helps the student access any general, eBook or other eresources from the digital library using the device provided by the institute itself. With the help of all these, the student can prepare for the assignments that are given to them as a part of their traditional learning model. The traditional learning model can also be introduced with several topics over the subject that has been taught in the class. The preparation of the assignments should be encouraged to be using digital resources and with the help of digital storytelling. This would not only ensure that the students are getting accustomed to the digitization techniques, but also that the modern technique of teaching leads all the activities for the preparation of the assignment with the help of digitized tools. The digitization factor would be introduced, here such that the teachers would figure out the most creative mind out of all the students through this assignment. Digital storytelling and its technique must be compulsory for the student to learn throughout their educational career. This would be extremely important for the accessing of the students based on the creative mind and the understanding that we could

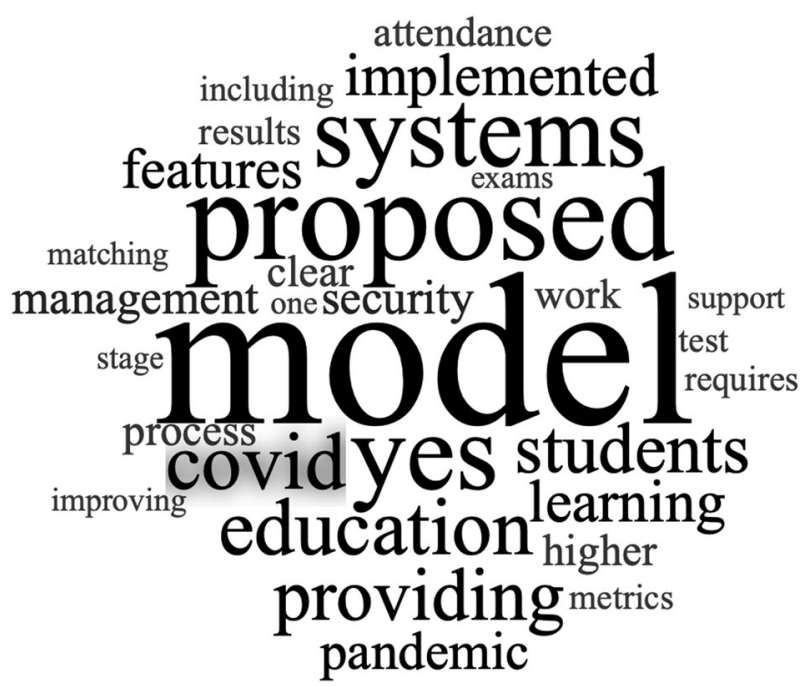

Fig. 3 Word cloud of top 25 most frequent words from the evaluation.

gather on the subject that has been taught to them through traditional forms of learning.

\section{Thematic evaluation}

Thematic analysis enables the scientists to decide exactly the connections among ideas and to think about them with the reproduced information. By utilizing thematic investigation, it is possible to interface the different ideas and feelings of the students and to contrast these and the information that has been assembled during the undertaking. NVIVO is generally acknowledged as a qualitative data investigation tool. NVIVO is intended for qualitative scientists working with exceptionally rich content-based, as well as mixed-media data, where profound dimensions of examination on small or extensive volumes of information are required. In addition, NVIVO is utilized prevalently by scholastic, government, wellbeing and business scientists across a wide range of fields, including sociology, as well as crime scene investigation. Likewise, NVIVO has a few favorable settings, for example,

Its capacity to infer the principal ideas in content and their relative significance

Its capacity to recognize the centrality of ideas

Its capacity to help with applying grounded hypothesis investigation to printed datasets

Its capacity to aid in outwardly investigating literary data for related subjects

This section aims to point out the artifact thematic evaluation results based on critical analysis conducted by NVIVO.

\section{Word frequency analysis results}

VIVO provides a variety of queries which give specialists a rundown of the ideas of referenced material or most frequently arising words. This can help the specialist not just to recognize conceivable topics, especially in the beginning periods of the task, but also to find the most continuous words occurring in a specific referenced material. The default setting of word recurrence questions is 1000 . Considering that the referenced material is an MS Word archive containing questions and replies from the five experts, it is trusted that the pursuit of the main 25 words' recurrence will provide a progressively significant and quick outcome. Figures 3 and 4 provide a full list of the most frequently occurring words. 


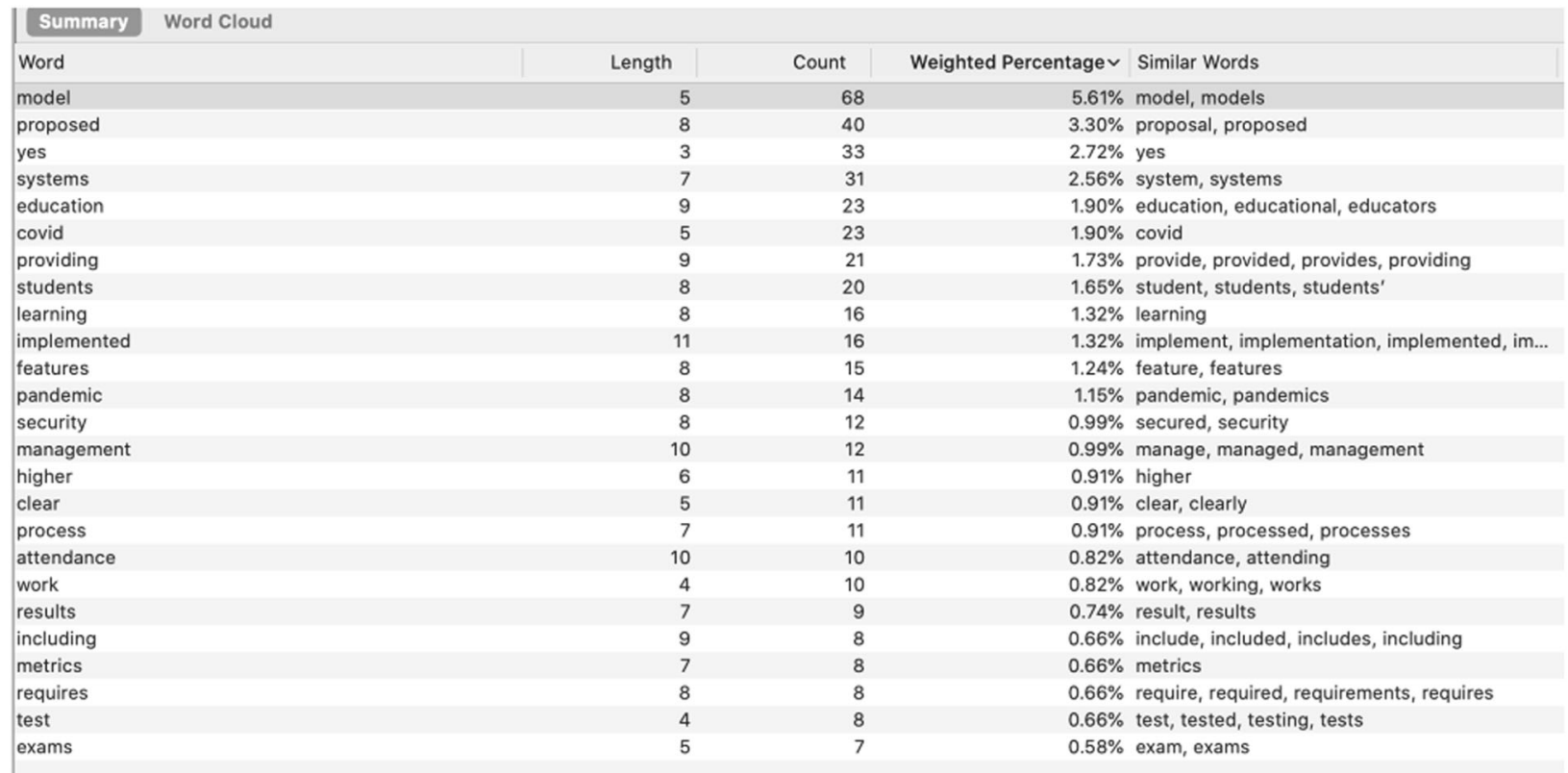

Fig. 4 Stemmed matching of top 25 most frequent words from the evaluation.

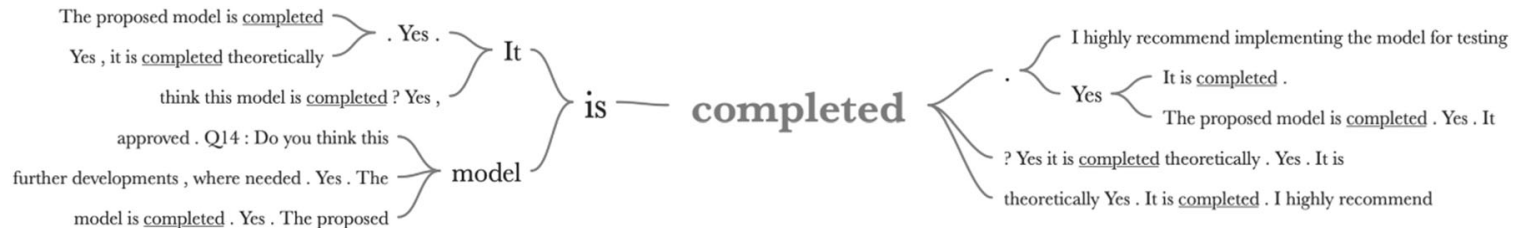

Fig. 5 Stemmed word query for "completed".
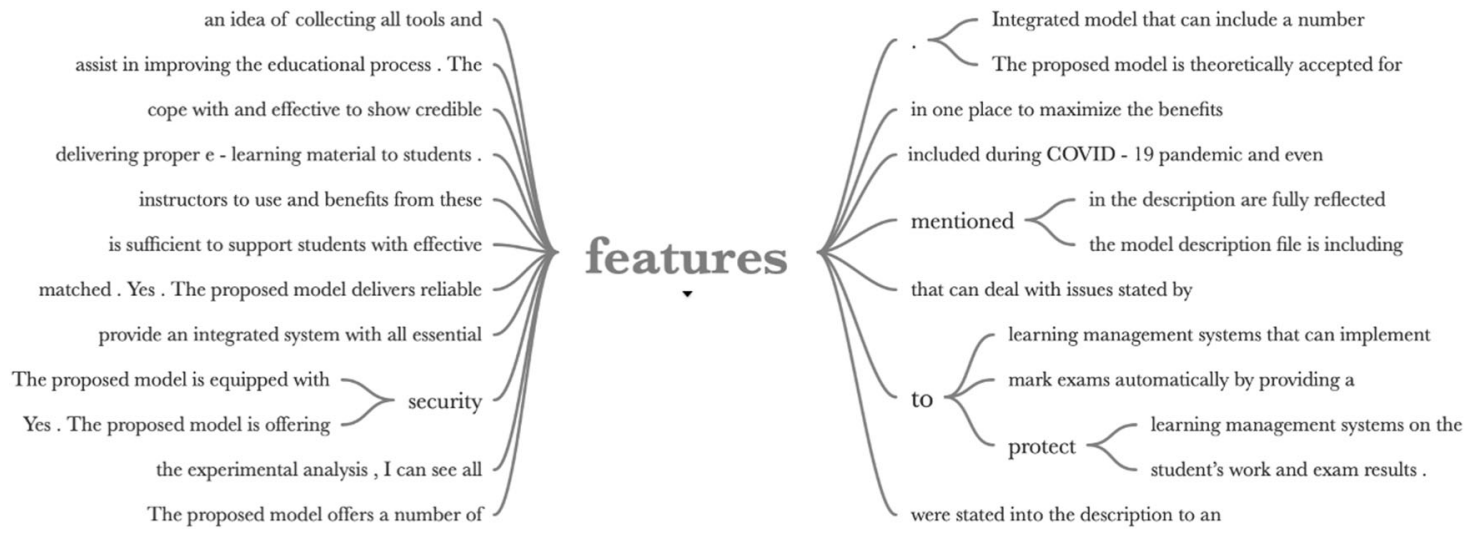

Fig. 6 Stemmed word query for "features".

Mutually the conclusions reveal that the third most frequent word in the leading evaluation is "yes" which shows up 33 times. The way that "yes" appears much of the time in the master evaluation proves that while each of the experts offers recommendations to improve the model, all experts give positive feedback to the proposed model. Therefore, it confirms that, in general, the analysis has accomplished its objective and structured reason.

\section{Text search analysis results}

Text search analysis can support the researcher in improving their conception of the proposal of the targeted words in links, with a significant requirement for critical thinking. The query of "text search" empowers the professional to look for expressions or words in submitted documents. It can be used to determine the application and meaning of words if a few deliveries are used more broadly in a specific content, to recognize if a subject or thought is persistent in the submitted document, and to look for notions that include similar words. The completion of the proposed model and the applicability of transitioning from the phases have been pointed out in this evaluation. Therefore, it reveals that a strong indication of how well the model is completed has been verified, as shown in Figs. 5-7. The outcome of a stemmed word query presents the same outcomes that reveal the consistency of the experts' feedback on the proposed model. However, if some query results from "exact word match" have been considered as effectively the same as "stemmed word match" 


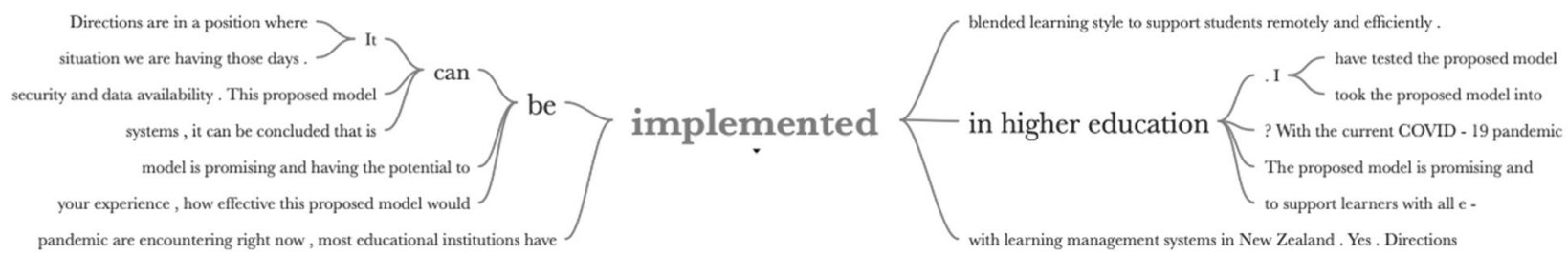

Fig. 7 Stemmed word query for "implemented".
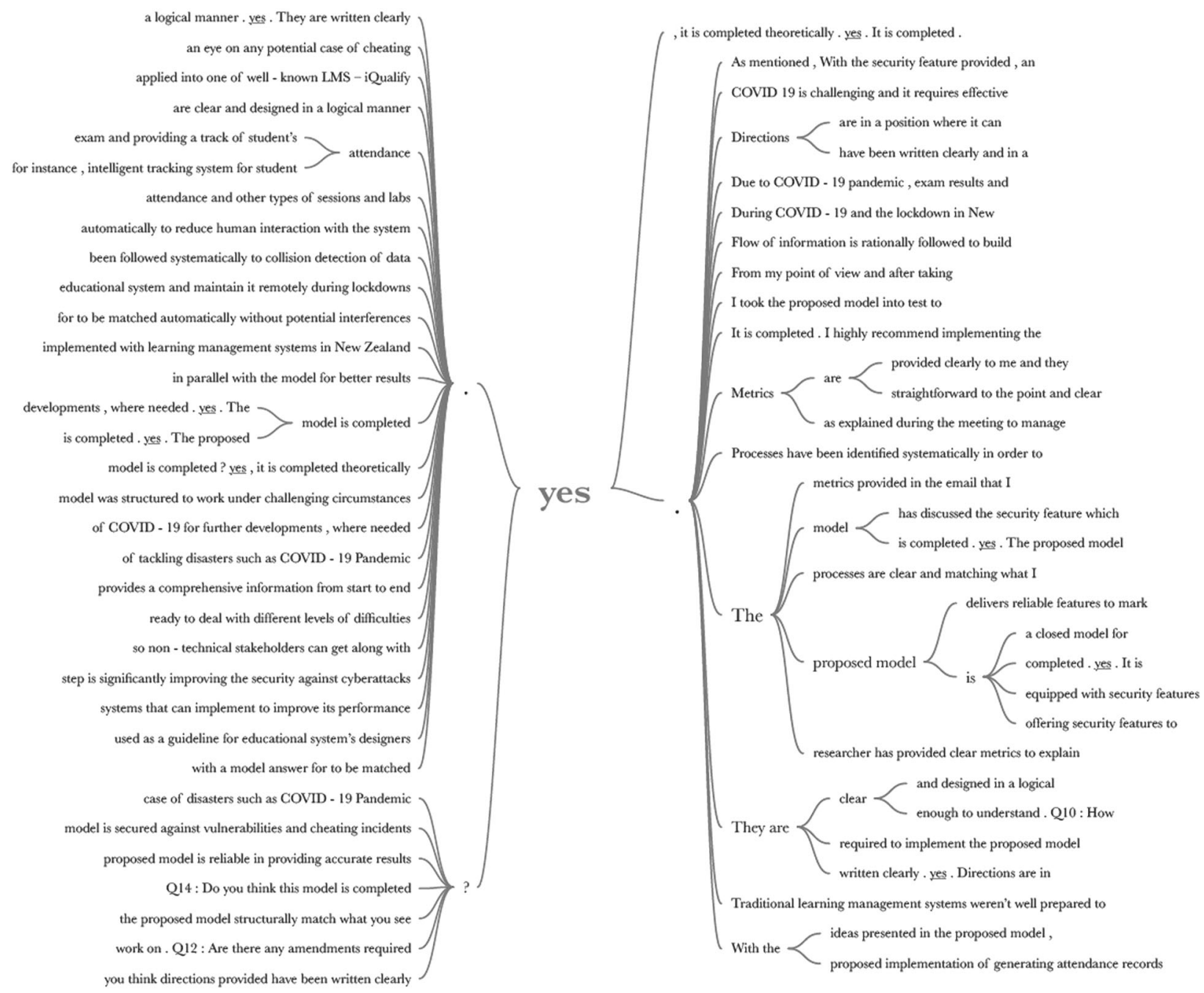

Fig. 8 Word tree "yes".

results, then only one of these results will be included in this evaluation for clarity with word tree in Fig. 8. The implementation process of the proposed model is discussed in the evaluation to provide detailed justification of how easily the proposed model can be implemented and adopted into higher education.

\section{Discussion: digitization of blended learning}

In this particular model, as proposed, there are several aspects that the students and the teachers can both use simultaneously for making the model work for the betterment of the studies. The individual teacher makes use of applications that would assist in the teaching. For example, teachers can use the applications along with the science curriculum that they are proposing to the students for learning about a simple and specific model. This application can be combined with the flipped classroom model as a way of helping the students focus more on the subject. With this particular logic, the students would learn the content of the application before the class, discuss the events that are occurring within the entire session and also use the application for additional information. The utilization of the digital technology is advised by the teachers in this module, where the students would be using these applications as assistant teachers or in a doubleteacher model.

The proposed system changes raise several challenges. During the study of this particular approach towards the blended learning module, it was found that the different ways in which the functionalities of blended learning modules work, especially digitization, could lead to challenges that could harm the students' experience, and therefore the implementation of the model would need to prioritize these issues. The first problem is the amount of time required to implement the learning module and 
to make the students learn the module and reflect on the learnings at the same time. The students also have an extremely tight schedule every day. Whenever the teachers are trying to squeeze some of the learning materials into the tight schedule, it becomes extremely difficult for the students, and so the introduction of a new way of learning seems to be an extremely time-consuming and difficult matter. The evaluation system for the teachers also comes with risks and must be carried out correctly so that the test-score-driven objectives are stuck to completely. The performance of the teachers should also be evaluated at the point of time when the digitized systems are being introduced. This is because the students and their performance are dependent on the performance of the teachers in utilizing the new model. Therefore, the teachers would also face considerable challenges in coping with the new system under consideration. However, changes in systems are inevitable even if it is a business or if it is a different perspective of the educational field. The system changes are rigidly test-driven because of the need to implement the best possible learning module for the students in New Zealand. Since the students are extremely focused on improving their creative skills and their academic skills at the same level, using digital systems might cause a problem in advancing their creative thinking abilities. The thinking abilities and creative mindsets of the students for their enhancement in the future are the sole priority of the people who are behind the development of this model. This development would greatly impact target students to improve their skills in online learning, self-concept, digital literacy, and self-efficacy (Le et al., 2019).

The primary problem that is to be defined in this particular proposal is about the understanding that leads to the blended learning model, and at the same time understanding the requirement for one of the most important aspects of the traditional educational model. This discussion would be about the implementation of the blended learning model with a digitization system and its utility in in analyzing the tests given. Tests are extremely important for evaluating the progress of a student in their respective educational fields. The understanding of each of these factors begins from making a student go through the learning models and then evaluating their skills and learnings gathered throughout the educational year for the semester with a set of testing questions. The learner-centered tools or digitized models that are being considered for use in this blended learning model are to identify the differences between the imagination of digitization used in the education system and the real scenario of how the students have been coping with their learning being substituted by digitized tools. So far, the researchers have found that the foremost benefit that the teachers and the students can gain from this is having a fast evaluation of the different types of test taken. The students who are appearing for the test would receive their results in no time if the teaching and test evaluation were assisted by a digitized model. This can be either a computer system or assisted virtual learning teachers. The evaluators can be totally automated by having a virtual teacher for the students ready for every instance. The adoption of learner-centered tools is extremely important, as is the re-imagining of tablets replacing the traditional teachers in a classroom using a personal learning portal for every student. Without the imagination of this scenario, there would not be any development towards the acceptance of this new proposal of a distributed blended learning model using digitalized versions of learning. Replacing the age-old systems and introducing the new and improved version of digital learning is highly appreciated. For the students in New Zealand, their focus on creative learning and their aim to stay ahead of all the universities throughout the world can be enhanced further with this model. The proper use of digitalization and the replacement of traditional teaching models are the focus of this educational model.
Blended learning models can improve the innovations in education in New Zealand. The implementation of digitization has been involved for the educational infrastructures, as they have already understood how digitizing the different aspects of education would provide them with growth and add value to the business. In the same way, digitization can be added to the different models of traditional learning in the education field. Finding a feasible knowledge for letting the traditional business model be substituted by digitization methods using blended learning activities as well is extremely necessary, because the students would be provided with several activities useful for their learning. Since this experiment in creating a blended learning model to replace the traditional way of conducting and educational lesson for the students in New Zealand, the studies have also found that the students in New Zealand would find it preferable as a model to be used so that the previous education methods used for New Zealand would not be harmed, even if digitization was the only thing changed in the business learning module.

Digitization and the blended learning model are particularly a curiosity of experimentation that can be put together for this new model that is proposed to be introduced. The potential of the discussed model is innovative, and these innovative pedagogies have never put to work together before in the field of education. A stronger understanding of the blended learning model is being developed in China to some extent; the type of learning that they follow in various Chinese universities and institutes has been one of the inspirations behind the development of this particular model. Experimental schools in China have implemented different educational practices, which have drawn on hundreds of reallife incidences to formulate a blended learning model so that students can experiment with the flipped classroom model from blended learning (Huang and Zhou, 2006). The flipped classroom model of blended learning has been used experimentally in China (Guangying, 2014). Throughout the research, it is recommended that for the students of New Zealand, it would be better to implement the model to discover how students' creativity could be given even more focus through the flipped classroom model and the simultaneous implementation of digitization to support the changes in the teaching styles from traditional setting.

\section{Conclusion}

Therefore, in conclusion, it can be said that the proper solution of the blended learning model and its implementation for the students of New Zealand can be found with the implementation of digitized blended learning, which would be beneficial for the students in New Zealand. The digitized model has been considered after understanding how the students in New Zealand are accustomed to learning and how their learning system is different from that of the rest of the world. During this understanding and learning, extensive research has been conducted to find out the differences between the students in New Zealand and the mode of learning that they receive. During this study, it has been found that the students in New Zealand are accustomed to the blended learning model which is in use in the current world. The educational industry has been researching the blended learning module and has found that supporting the ways by which learning can be blended would also be useful for analyzing how the blended learning models also replicate testing for teachers and students alike. The digitization of the blended learning model is thus proposed as an appropriate model that would help in the detection of how both the students and the teacher are performing in examinations. These examinations would not just evaluate the students based on their performance and understanding of the knowledge areas but would also examine the skills 
obtained by the teacher and how they have been effectively teaching their allotted class. This can provide a very significant role to the digitized teachers used for this particular area of studying. The digital teacher would act as the proper substitute for a teacher to the students when they encountered any problem or when the tight schedule of both the students and teachers made it impossible for the teachers to provide any assistance to the students. The developed model would be based on how the teachers and students interacted so that the interaction between the assistant teachers and students could be monitored and programmed well.

\section{Data availability}

The data generated during this study is not publicly available due to privacy concerns.

Received: 27 January 2020; Accepted: 25 November 2020;

Published online: 16 March 2021

\section{References}

Al-Busaidi KA (2012) Learners' perspective on critical factors to LMS success in blended learning: an empirical investigation. Commun Assoc Inform Syst 30 (2):11-34. https://doi.org/10.17705/1CAIS.03002

Barlow C (1991) Tikanga whakaaro: key concepts in Maori culture. Oxford University Press, Auckland

Basir HM, Ahmad, A, Noor NLM (2010) Institutional strategy for effective blended e-learning: HCI perspective of sustainable embedding. In: 2010 International Conference on User Science and Engineering. IEEE, Shah Alam, Malaysia, pp $71-76$

Belov M, Cheremisina E, Potemkina S (2016) Distance learning through distributed information systems using a virtual computer lab and knowledge management system. J Emerg Res Solu ICT 1(2):39-46

Bidarra J, Rusman E (2017) Towards a pedagogical model for science education: bridging educational contexts through a blended learning approach. Open Learn 32(1):6-20

Boelens R, Voet M, De Wever B (2018) The design of blended learning in response to student diversity in higher education: Instructors' views and use of differentiated instruction in blended learning. Comput Educ 120:197-212

Bokolo Jr A, Kamaludin A, Romli A, Mat Raffei AF, A/L Eh Phon DN, Abdullah A, Baba S (2020) A managerial perspective on institutions' administration readiness to diffuse blended learning in higher education: concept and evidence. J Res Technol Educ 52(1):37-64

Borba MC, Askar P, Engelbrecht J, Gadanidis G, Llinares S, Aguilar MS (2016) Blended learning, e-learning and mobile learning in mathematics education. ZDM 48(5):589-610

Broadbent J (2017) Comparing online and blended learner's self-regulated learning strategies and academic performance. Internet High Educ 33:24-32

Chan S (2010) Applications of andragogy in multi-disciplined teaching and learning. J Adult Educ 39(2):25-35

Chang XQ, Zhang DH, Jin XX (2016) Application of virtual reality technology in distance learning. Int J Emerg Technol Learn 11(11):76-79

Chellapan L, Van der Meer J, Pratt K, Wass R (2018) "To flip or not to flip, that's the question"-Findings from an exploratory study into factors that may influence tertiary teachers to consider a flipped classroom model. J Open Flexible Distance Learn 22(1):6-21

Chen WS, Yao AYT (2016) An empirical evaluation of critical factors influencing learner satisfaction in blended learning: a pilot study. Universal J Educ Res 4 (7):1667-1671

Clark JT (2020) Distance education. Clin Eng Handbook 58(9):89-95. In

Crawford R (2017) Rethinking teaching and learning pedagogy for education in the twenty-first century: blended learning in music education. Music Educ Res 19 (2):195-213

Cuesta Medina L (2018) Blended learning: deficits and prospects in higher education. Australasian J Educ Technol 34:1

Dellatola E, Daradoumis T, Dimitriadis Y (2020) Exploring students' engagement within a collaborative inquiry-based language learning activity in a blended environment. In: Emerging Technologies and Pedagogies in the Curriculum. Springer, Singapore, pp 355-375

Dziuban C, Graham CR, Moskal PD, Norberg A, Sicilia N (2018) Blended learning: the new normal and emerging technologies. Int J Educ Technol High Educ 15(1):3
Fathema N, Shannon D, Ross M (2015) Expanding the Technology Acceptance Model (TAM) to examine faculty use of Learning Management Systems (LMSs) in higher education institutions. J Online Learn Teach 11:2

Forrest III SP, Peterson TO (2006) It's called andragogy. Acad Manag Learn Educ 5 (1):113-122

Frampton M (2016) Implementation of a Blended learning Educational model on the Mental Health Act 2001 for Trainee Psychiatrists. In: Leading Change as a Professional. Vol. 109

Ghazal S, Al-Samarraie H, Aldowah H (2018) "I am Still Learning": modeling LMS critical success factors for promoting students' experience and satisfaction in a blended learning environment. IEEE Access 6:77179-77201

Graham CR (2013) Emerging practice and research in blended learning. Handbook Distance Educ 3:333-350.

Guangying C (2014) An experimental research on blended learning in the development of listening and speaking skills in China. South African Linguist Appl Lang Stud 32(4):447-460

Han F, Ellis RA (2019) Identifying consistent patterns of quality learning discussions in blended learning. Internet High Educ 40:12-19

Havemann L, Charles E, Sherman S, Rodgers S, Barros J (2019) A multitude of modes: considering 'blended learning' in context. In: CDE RIDE Conference 2019, 15 Mar 2019, London

Hemara W (2000) Maori pedagogies: a view from the literature. New Zealand Council for Educational Research, Wellington

Huang R, Zhou Y (2006) Designing blended learning focused on knowledge category and learning activities. In: The Handbook of Blended Learning: Global Perspectives, Local Designs. pp 296-310

Huang R, Spector JM, Yang J (2019) Emerging issues in educational technology. In: Educational Technology. Springer, Singapore, pp 231-241

Jennex M (2020) Managing crises and disasters with emerging technologies: advancements. Open Government 2580 (pp 84-117)

Johns C (2017) Mental Health and Wellbeing in New Zealand Education. J Initial Teacher Inquiry 3

Khodabandelou R, Ab Jalil H, Ali WZW, Daud SM (2017) Presence and perceived learning in different higher education blended learning environments. In Blended Learning: Concepts, Methodologies, Tools, and Applications. IGI Global. pp 615-627

Kristanto A (2017) The development of instructional materials E-learning based on blended learning. Int Educ Stud 10(7):10-17

Kut V, Kunanets N, Pasichnik V, Tomashevskyi V (2018) The procedures for the selection of knowledge representation methods in the "virtual university" distance learning system. Int Conf Comput Sci Eng Educ Appl 25 (9):713-723

Le B, Woods G, Wang J, Lawrie G (2019) Digital literacy skills, student interactivity and academic performance in STEM blended course. In: Proceedings of the Australian Conference on Science and Mathematics Education (formerly UniServe Science Conference). p. 61

Logan E, Augustyniak R, Rees A (2002) Distance education as different education: a student-centered investigation of distance learning experience. J Educ Library Inform Sci 43:32-42

Lu OH, Huang AY, Huang JC, Lin AJ, Ogata H, Yang SJ (2018) Applying learning analytics for the early prediction of Students' academic performance in blended learning. J Educ Technol Soc 21(2):220-232

Malfliet A, Kregel J, Meeus M, Roussel N, Danneels L, Cagnie B, Nijs J (2018) Blended-learning pain neuroscience education for people with chronic spinal pain: randomized controlled multicenter trial. Phys Therapy 98 (5):357-368

Manwaring KC, Larsen R, Graham CR, Henrie CR, Halverson LR (2017) Investigating student engagement in blended learning settings using experience sampling and structural equation modeling. Internet High Educ 35:21-33

McLaren IA (2018) Education in a small democracy. Routledge, New Zealand

Merriam SB, Caffarella RS, Baumgartner LM (2007) Learning in adulthood: a comprehensive guide, 3 rd edn. Jossey-Bass, San Francisco

Montgomery AP, Mousavi A, Carbonaro M, Hayward DV, Dunn W (2019) Using learning analytics to explore self-regulated learning in flipped blended learning music teacher education. Br J Educ Technol 50(1):114-127

Moskal P, Dziuban C, Hartman J (2013) Blended learning: a dangerous idea? Internet High Educ 18:15-23

Nortvig AM, Petersen AK, Balle SH (2018) A literature review of the factors influencing e-learning and blended learning in relation to learning outcome, Student Satisfaction and Engagement. Electronic J E-learn 16(1):46-55

Otto D (2018) Using virtual mobility and digital storytelling in blended learning: analysing students' experiences. Turkish Online J Distance Educ 19 (4):90-103

Pandit RK (2018) Blended learning. Madhav Institute of Technology and Science, Gwalior

Park Y, Yu JH, Jo IH (2016) Clustering blended learning courses by online behavior data: a case study in a Korean higher education institute. Internet High Educ 29:1-11 
Pierce D (2017) What effective blended learning looks like: no two blended learning classrooms will look exactly alike-but here are some common elements for success. J Technol Horizons Educ 44(1):18

Pilgrim M, Hornby G, Macfarlane S (2018) Enablers and barriers to developing competencies in a blended learning programme for specialist teachers in New Zealand. Educ Rev 70(5):548-564

Plump CM, LaRosa J (2017) Using Kahoot! in the classroom to create engagement and active learning: a game-based technology solution for eLearning novices. Manag Teach Rev 2(2):151-158

Porter WW, Graham CR, Bodily RG, Sandberg DS (2016) A qualitative analysis of institutional drivers and barriers to blended learning adoption in higher education. Internet High Educ 28:17-27

Shaffer K, Small JE (2004) Blended learning in medical education: Use of an integrated approach with web-based small group modules and didactic instruction for teaching radiologic anatomy1. Acad Radiol 11(9):1059-1070

Sosa E, Salinas J, De Benito B (2019) Emerging technologies (ETs) in education: a systematic review of the literature published between 2006 and 2016. Int J Emerg Technol Learn 12(5):128-149. 2017

Spring KJ, Graham CR, Hadlock CA (2016) The current landscape of international blended learning. Int J Technol Enhanced Learn 8(1):84-102. https://doi.org/ 10.1504/IJTEL.2016.075961

Starkey L (2020) A review of research exploring teacher preparation for the digital age. Cambridge J Educ 50(1):37-56

Stroeva OA, Zviagintceva Y, Tokmakova E, Petrukhina E, Polyakova O (2019) Application of remote technologies in education. Int J Educ Manag 33(3):503-510

Thompson K, Jowallah R, Cavanagh TB (2019) "Solve the Big Problems": Leading Through Strategic Innovation in Blended Teaching and Learning. In: Technology Leadership for Innovation in Higher Education. IGI Global. pp 26-48

Van den Bogaart T, Drijvers PHM, Tolboom J (2017) The design and use of open online models for blended learning in STEM education. In: Proceedings of the 13th International Conference on Technology in Mathematics Teaching. Universite de Lyon. pp 339-346

Vo HM, Zhu C, Diep NA (2017) The effect of blended learning on student performance at course-level in higher education: a meta-analysis. Stud Educ Eval $53: 17-28$
Zainuddin Z, Chu SKW, Shujahat M, Perera CJ (2020) The impact of gamification on learning and instruction: A systematic review of empirical evidence. Educ Res Rev 100326

Zepke N, Leach L (2002) Appropriate pedagogy and technology in a crosscultural distance education context. Teach High Educ 7(3):309-321

\section{Competing interests}

The authors declare no competing interests.

\section{Additional information}

Correspondence and requests for materials should be addressed to A.A.

Reprints and permission information is available at http://www.nature.com/reprints

Publisher's note Springer Nature remains neutral with regard to jurisdictional claims in published maps and institutional affiliations.

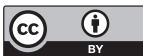

Open Access This article is licensed under a Creative Commons Attribution 4.0 International License, which permits use, sharing, adaptation, distribution and reproduction in any medium or format, as long as you give appropriate credit to the original author(s) and the source, provide a link to the Creative Commons license, and indicate if changes were made. The images or other third party material in this article are included in the article's Creative Commons license, unless indicated otherwise in a credit line to the material. If material is not included in the article's Creative Commons license and your intended use is not permitted by statutory regulation or exceeds the permitted use, you will need to obtain permission directly from the copyright holder. To view a copy of this license, visit http://creativecommons.org/ licenses/by/4.0/.

(C) The Author(s) 2021 